\title{
Palabra: articulación y encuentro desde el mito y la leyenda
}

\section{Word: articulation and encounter from myth and legend}

\author{
Ronald Obando Brenes ${ }^{1}$ \\ Instituto de Estudios Latinoamericanos \\ Universidad Nacional, Costa Rica \\ ronald.obando.brenes@una.cr
}

\begin{abstract}
Resumen
Palabra es la estructura del universo. La Palabra resuelve su cualidad creadora desde lo abstracto. Poder elevar la comprensión de los significados a significaciones concretas conlleva despejar la raíz elemental de aquellos momentos en que la oralidad se cuela en la memoria mediante diversas maneras de transmisión hereditaria. Conocer, en la palabra, su antevenir en el mito o la leyenda es esencial para reconocer los roles de la memoria en la identidad. El artículo entreteje los hilos de la relación mito-imaginación-expresión-lenguaje-memoria-identidad y Palabra.
\end{abstract}

Palabras clave: mito, leyenda, imaginación, expresión, lenguaje, memoria, identidad, Palabra.

\begin{abstract}
Word is the structure of the universe. The word resolves its creative quality from the abstract. Being able to elevate the comprehension of meanings to concrete meanings involves dispelling the elementary root of those moments in which orality sneaks into memory through various ways of hereditary transmission. Know in the word; its anteversion in myth or legend is essential to recognize the roles of memory in identity. The article weaves together the threads of the relationship between myth-imagination-expression-language-memory-identity and Word.
\end{abstract}

Keywords: Myth, legend, imagination, expression, language, memory, identity, Word.

1 Este artículo está basado en su tesis: Cachi, Leyenda y Palabra del autor de este artículo, Ronald Obando Brenes. 
"Si el habla nos une como parejas, como sociedades, como pueblos; entonces, hablamos porque somos, pero somos porque hablamos" (Cortázar, 1981).

\section{Destejer mito y palabra}

D esde el momento en que se accede desde la palabra como primigenia forma de expresión cultural, se cultiva un florecimiento de aprendizajes básicos, originarios, endógenos, sustantivos y con una vitalidad integradora de la que se derivan todas las demás formas de comprensión socioculturales.

El lenguaje es el vehículo natural y perfecto para la transmisión de los pensamientos; por lo que se dice que nunca llegaría a perder su aspecto poético original.

Ciertamente, el valor de la poesía funge como un hacedor natural de mitos, según Müller (en Gusdorf, 1971, p. 90), y más allá del lenguaje; entonces, la Palabra viene a conservar su manifestación intrínseca en el lenguaje mítico esencial.

Tanto los mitos como su derivación en leyendas mantienen una indisoluble importancia entre los elementos físicos y metafísicos; entre lo concreto y lo abstracto.

Para el filósofo e historiador francés George Gusdorf, los hilos del lenguaje-mito son una relación prioritaria (Gusdorf, 1971, p. 15). Éste define que el primer lenguaje llega a ser el llamado lenguaje esencial, y que, sencillamente, también posee un valor mágico y religioso; más cercano a lo espiritual $\mathrm{y}$ a valores fundados en creencias.
Por otra parte, Vygotsky dio por sentado que la unidad básica del análisis semiótico es la Palabra (Wertsch, 1988, p. 144). Sin embargo, al enunciar Palabra pensamos en el conjunto de todos los elementos simbólicos que dan contenido a la comprensión de vidas: pensamientos, ideas, discursos, sueños, anhelos, sentimientos, visiones, utopías, percepciones, sensaciones, razones, desazones, interpretaciones, criticismos, reflexiones, propuestas, aprendizajes, construcciones, condiciones y saberes.

Primeramente, conocer el mundo físico parte por la recreación de su propia imagen simbólica.

Los sujetos se ocupan de crear significados, de resolver problemas de un modo imaginativo y de producir problemas con igual creatividad. En consecuencia, el ser viviente se ha envuelto a tal punto en formas lingüísticas, imágenes artísticas, saberes míticos y prerrogativas religiosas que no puede ver, ni conocer nada si no es con la mediación del instrumento simbólico (Gardner, 1987, p. 65).

Asimismo, las personas viven en medio de emociones imaginarias, de esperanzas y temores, ilusiones y decepciones, fantasías y sueños, según lo enuncia Cassirer (1944, en Moreno, Gendrik, 2017, p. 25).

Empero, no toda comprensión es mediada a través del lenguaje.

El mito sobresale porque posee una amplitud de comprensibilidad muy ancha y está unida simbióticamente a la Palabra. 
Podría decirse que el mito nunca desaparecerá, debido a que el lenguaje tampoco podría compararse al pensamiento mismo. El lenguaje per se no resuelve las innumerables interpretaciones que derivan del valor abstracto, espiritual y metafísico que contienen los mitos.

No obstante, en la Palabra se intermedia un simbolismo material con otro inmaterial, que a nivel expresivo se traduce en acciones; pero, además, en inhibiciones.

Una cualidad de la Palabra es que orienta $\mathrm{y}$ desorienta todo aquello que dice y que no dice; que hace o que deja de hacer. Esto quiere decir que la Palabra tiende a perderse entre olvidos, a auscultarse entre desencantos y silencios. Muchas razones tácitas $\mathrm{y}$ de facto permiten su visibilidad o coaccionan su desvanecimiento (de la palabra).

Precisamente, en las palabras no dichas se pueden hallar deliberaciones exponencialmente más críticas que sobre aquellas que son expresas, por su "natural" función de contención social y formas de resiliencia.

La Palabra no dicha es la expresión cruda del sometimiento; es una respuesta a la represión; es una misma crítica inteligible que desvalida los triunfos de la historia sobre la memoria. Decía Gandhi que el silencio ayuda mucho a quien procura conocer la verdad.

Por otra parte; Gusdorf menciona que si bien, en algunas culturas, la lengua-muerta invoca a valores ausentes; ciertamente la palabra-viviente, manifiesta la exigencia de una vida espiritual en su tarea cotidiana; por tanto; la palabra no llega a ser un sistema cerrado o acabado; sino es todo lo contrario; es dinámico y está en constante esfuerzo de regeneración (1971, p. 40).

Después de todo; la evocación del pasado resulta necesaria, en la medida en que se trata de un complejo mecanismo que hace posible la construcción de referentes que dinamizan el presente vivido colectivamente (Halbwachs, 1997; Joutard, 1977; Ricoeur, 1999).

En tal sentido, la persistencia del recuerdo como elemento constitutivo de la palabra evoca naturalmente la lucha de la memoria y con tal se constituye una práctica permanente que es, al mismo tiempo, un proceso de invención, de recreación, de afirmación o de expulsión de unos significados o de imposición o asimilación de otros.

Por lo tanto; el recuerdo posee implícitamente una significación que afecta. En consecuencia, cualquier efecto o variación de la Palabra, llámese afirmación, negación, desconocimiento o silencio, implícitamente, resguarda un momento del tiempo al presente.

Aunque el uso de la palabra se manifiesta acorde con su tiempo y contextos; por su parte, el Mito como Palabra se readecúa, se contextualiza y se actualiza para persistir o perdurar en la memoria colectiva.

Como un acto puro de sistematización, la memoria recoge esas experiencias del pasado; genera una interacción entre el recuerdo y el no recuerdo; entre los actos consientes y los actos inhibidos que los imaginarios se han intercambiado y cuya correspondencia de comprensiones se transforma dinámicamente en conjunto con otros saberes ajenos. 


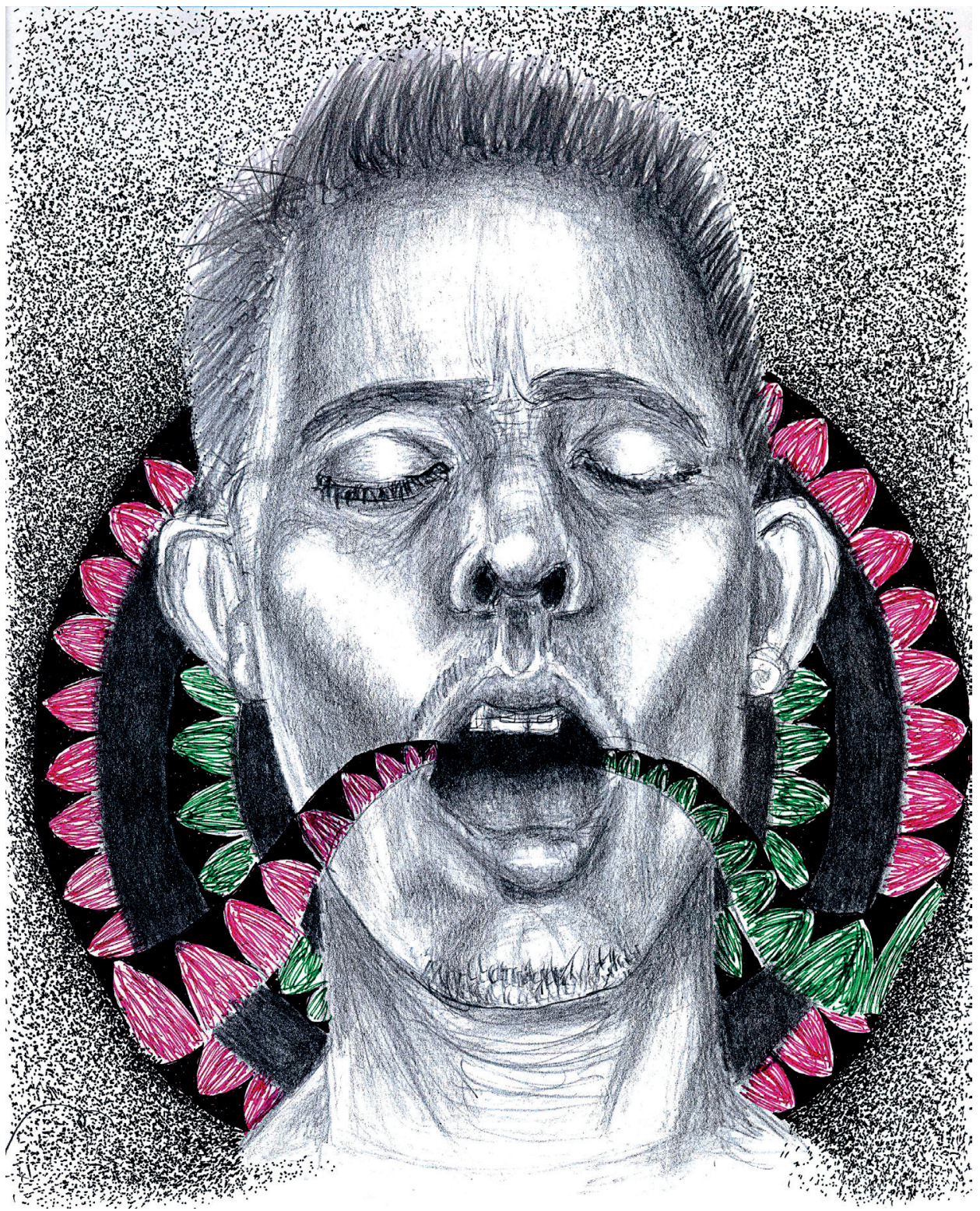

Autorretrato

\section{Jesús Esteban Vargas Cordero}

Técnica: mixta, 2018.

Ilustra el artículo

Palabra: articulación y encuentro desde el mito y la leyenda 
Podría decirse que la producción de significados hechos Palabra se desplaza tangencialmente en una imaginaria línea elíptica con forma espiral que representa los puntos indivisibles de su tiempo transcurrido; y que, al final de todo, compila; recupera y da sentido a la tenencia de más memoria.

Por otra parte; el hilo lenguaje-expresión es otro factor clave que suma al proceso.

Aunque la comunicación contiene una virtud creadora; a la expresión le corresponde ser aquel coeficiente mínimo de la Palabra que realiza un equilibrio con el coeficiente de la comunicación (Gusdorf, 1971).

Aunque corresponde al lenguaje fundamentar la parte real-concreta de la palabra; a la expresión le corresponde recibirla del pensamiento y darle su nacimiento; esa mínima acción es la interface necesaria de apropiación entre la acción física y la acción espiritual; fundamental en el acervo metonímico de la Palabra.

En consecuencia, el mito como creencia cultural también se aproxima a un valor relativo; ya que su comprensión (como reflejo de una creencia) nace al entretejerse armónicamente a la realidad-con-el-lenguaje y a la-ficción-con-el-pensamiento; pero enraizando sus bifurcaciones desde la imaginación.

Entre tanto; la relación creativa "imaginación-mito" no necesita entrar en discursos de análisis tan profundos ni asumir complicadas comprensiones; más bien le es benéfico dejarse amorfo y abstracto.
Lo anterior garantiza a la Palabra su máxima validez; así como su multiplicidad de significados; confiriéndole una expresividad cultural, social y artística muy propia y abierta. Mientras tanto; la oralidad se encarga de testificar y heredar los saberes de esa creación imaginaria en forma de mitos.

No obstante; para Hume: "una imaginación poderosa era la capacidad de convertir las ideas en impresiones vivas, de despertar pasiones reales y de experimentarlas, en terrenos como el reflejo en experiencias pasadas o los hechos de otras personas" (Warnock, 1976, p. 345).

De ahí que la muestra mítica está "en cierto modo" atada para producir y reproducir las ideas en el mismo orden en que se recibieron las impresiones originales. En tanto que la imaginación tiene la libertad de trasponer y cambiar en forma libre sus ideas (Warnock, 1976). En este juego procesional se entretejen la expresión y el lenguaje.

Y entonces, si desde la expresión se busca dar sentido a lo real, le tocaría al lenguaje oral ser el medio que permite anclar y aterrizar la Palabra.

En definitiva; todas las variedades del grito, el aullido, la exclamación, la interjección, y el voto aparecen como esfuerzos para adaptar el yo a un mundo que se sustrae. La sorpresa, la alegría, el miedo y el espanto aproximan la Palabra a una emoción pura.

Y, por último, ante emociones como la angustia, la tortura, o la muerte solo queda el recurso del grito, como el último intento 
desesperado e invocado en el supremo llamado de la conciencia, mediante la eficacia mágica de su clamor: del clamor de la última Palabra (Gusdorf, 1976).

\section{Entretejer palabra critica}

Paulo Freire alertaba que, si ciertamente, "la realidad es lo que es"; entonces ¿qué podemos hacer ante eso? Una manera originaria de responder es revertir la tendencia al olvido de nuestras propias expresiones orales y culturales inmateriales.

Para Vygostky, los mecanismos semióticos de la cultura son los elementos mediadores de cualquier actividad humana (Wertsch, 1988). Desde esta perspectiva de aprendizaje psico-socio-cultural, la importancia de los mitos y leyendas deriva en varias razones:

a. que la palabra desde su lingüística posee en la leyenda un valor mítico poético esencial;

b. que los significados acaecidos en los mitos no son unidimensionales y que el terreno de su alcance semántico no es universal (Brisson, citado por Vitsaxis, 2007, p. 36), por lo que podrían considerarse como una expresión cultural originaria muy autentica.

Ciertamente, el uso de mitos y leyendas no se caracteriza por narrar hechos reales con rigurosidad o exactitud; sino, más bien, su finalidad ha servido para subrayar los componentes espirituales o intenciones asociadas a la moral y a las buenas costumbres pluriculturales.
De ahí que en su reflejo físico, además de poseer una función educativa realizadora; también conlleva una lógica social, artística y estética en la cual los resultados del pensamiento mitológico inmaterial llegan al conocimiento del sujeto porque son expresados materialmente en signos exteriores (como lo plástico, lo pictórico, lo mímico).

Sin embargo, "el mito es preferentemente una obra verbal; y de los dos tipos de obras verbales (como poesía y prosa), el mito pertenece al primero..." (Potebniá; citado por I. Savranski, 1983, p. 111).

Igualmente; la singularidad de la expresión cultural mitológica también se concibe al conquistar espacios exóticos en donde las coordenadas de espacio-tiempo son esenciales en la configuración de la identidad local (Monge Amador; 1997); sobre todo en aquellos lugares donde se desarrollaron procesos de "exclusión-inclusión". Es posible que la leyenda, más que el mito, tienda a ser más localizada, específica, ubicada en tiempo y espacios.

Otro fundamento intrínseco hallado en el uso de los mitos y leyendas radica en la fidelidad expresiva de su narración.

De ahí que esa característica brota con mayor fuerza en los llamados espaciosnúcleos donde habitan culturas con condiciones más cercanas a las originarias; culturas que subyacen aún como una flor dormida, señala Linton (1973); y que han contenido siempre sus indivisos valores como "núcleo" en "la centralidad cultural" del "lugar antropológico" menciona Augé (en Ortiz, 1998, p. 45). 
Por otra parte, por razón de la autocrítica, textos filosóficos como los de Hume consideran que el "yo" no llega a ser otra cosa que un puñado de sensaciones (Hume, 1739; véase Blackmore, 2000); mientras que Claxton añade que la conciencia es solo un mecanismo para construir excusas (Blackmore, 2000). Prácticamente, Hume religa una imaginación poderosa a la capacidad de convertir las ideas en impresiones vivas.

Con lo anterior, cabe resaltar que una recuperación oral de mitos y leyendas está en cierto modo atada a producir y reproducir las ideas y sucesos nativos acontecidos en el mismo orden temporal en que se recibieron sus impresiones originales. Entre tanto; la imaginación actúa o resuelve la libertad de trasponer y cambiar en forma libre sus ideas a ideas más poderosas y sus experiencias comunes a impresiones vivas, trascendentales o fantasiosas (Blackmore, 2000).

Por consiguiente, creer en la propia palabra supone un sentido de autenticidad único.

Del mismo modo, podría contemplarse la leyenda como una experienciación entre lo físico y lo espiritual, que recobra un sentido dialógico de aprendizaje "cuando lo-comprendido es experimentado emocionalmente; implicando una relación recíproca sobre las facultades del ser humano" (Frankfort, 1958, p. 16).

Por tanto, poder creer en las posibilidades de la palabra como un conocimiento impreso en la emoción devenida de un grito o una lágrima sencillamente argumenta y valida, con mayor convencimiento ante los demás sujetos, que efectivamente un hecho sí existió, y que de este nos queda una memoria oral remota común compartida en leyendas.

Básicamente, resulta en que el poder de la leyenda es que logra "metaforizar lo real" y "esencializar lo fantasioso" en una legítima y armoniosa coexistencia. Asimismo, en cierto modo, la propia magia que evoca el misterio de una leyenda cumple una funcionalidad social endógena para apropiar la psique de los sujetos-actores en torno a su memoria colectiva.

Contrario a otras formas de cultivo (exógenas, artificiales o impuestas) de la Palabra, como, por ejemplo, las técnicas más elevadas en la retórica, la dialéctica y la sofistica (Frankfort, 1958); la fluidez natural del mito o la leyenda se refuerzan en la cultura popular y con el atributo único de su sencillez.

De tal manera, una comunidad de valores conforma el lenguaje de una cultura unitaria (Frankfort, 1958); por tanto, su palabra resurge como elemento constitutivo de su propio encuentro.

De lo anterior cabe resaltar que la sublimación de la Palabra como Leyenda yace, precisamente, en evocar una grandeza cósmica trascendental, al vencer y resolver el conflicto de la existencia, desalojando temores y, a la vez; reconociendo la propia insignificancia cósmica; pero haciéndose capaz de soportar la propia verdad.

En conclusión; por esa razón y en cierto sentido, la Palabra se torna verdad y la verdad se hace Palabra a través de procesos o experiencias rituales del mito, porque refresca la memoria y la actualiza. 
Por consiguiente, si la leyenda subyace entre mito y verdad; entonces, la Palabra podría entretejer, en la Leyenda, su forma más auténtica; pero, a la vez, frágil de expresividad cultural.

Se diría, entonces, que la simbiosis depende profusamente del propio poder de su palabra.

\section{Referencias}

Blackmore, Susan. (2000). La máquina de los memes. Buenos Aires: Editorial Paidós.

Freire, Paulo. (2012). Pedagogía del oprimido. Buenos Aires: Siglo XXI.

Gardner, Howard. (1999). Educación artística y desarrollo humano. Barcelona: Editorial Paidós.

Gusdorf, Georges. (1971). La Palabra. Buenos Aires: Ediciones Nueva Visión.

Monge Amador, Jorge. (Agosto-diciembre, 2008). El perfil de la autoimagen en la literatura costarricense y el discurso de la postmodernidad latinoamericana. Revista Comunicación, 17 (002).
Moreno, Gendrik (2017). Ernst Cassirer. Hacia una comprensión simbólica del lenguaje. Ágora - Trujillo. Revista del Centro Regional de Investigación Humanística, Económica y Social, 19(37), 89-119.

Ortiz, Renato. (1998) Modernidad, mundo e identidad. En Otro territorio: Ensayos sobre el mundo contemporáneo (pp. 43-67). Bogotá: Convenio Andrés Bello.

Ricoeur, Paul. (2003). La memoria, la historia, y el olvido. Madrid: Editorial Trotta.

Savranski, I. (1983). La cultura y sus funciones. Moscú: Editorial Progreso.

Vasilis Vitsaxís. (2007). El mito: Punto de referencia en la búsqueda existencial. Buenos Aires: Editorial Teseo.

Warnock; Mary. (1976). La imaginación. México: Fondo de Cultura Económica.

Wertsch, James. (1988). Vygotsky y la formación social de la mente. Barcelona: Editorial Paidós. 